\title{
Persistent Proteinuria in Children
}

\author{
Y. C. TSAO, W. C. CHAN, and J. B. GIBSON \\ From the Departments of Paediatrics and Pathology, University of Hong Kong
}

Proteinuria may be considered persistent in a child when it lasts longer than 3 weeks. Since 1963 we have investigated persistent proteinuria of all degrees of severity in children admitted to hospital in Hong Kong. In most of the cases the proteinuria was idiopathic; in others it was secondary to a recognized renal disease. Renal biopsy was carried out in all of them and repeated in many to establish a histological diagnosis. Most of the biopsies were examined for the presence of globulins in the lesions. Urinary differential protein clearances were estimated in many cases. The study, which is still in progress, has reached a stage where it is possible to make a correlation of the biopsy and other findings with the clinical presentation and with the response to treatment and short-term prognosis.

\section{Clinical Data and Methods of Investigation}

There were 176 patients aged between 2 and 12 years at the time of the study, of whom 129 were boys and 47 were girls. They representer a typical cross-section of the Chinese population of Hong Kong. Proteinuria of more than 3 weeks' duration was the sole criterion for including a child in the study, and in most of the cases proteinuria was known to have been present for several months and in some for 3 to 4 years. The cases can be divided according to their clinical features as follows.

Idiopathic nephrotic syndrome $(67 \%)$. These 119 patients, of whom 25 were girls, presented with gross oedema, often with ascites, heavy proteinuria of up to 6-7 g. in 24 hours, and low serum proteins. In many, the serum albumin was less than $1 \mathrm{~g} .100 \mathrm{ml}$., the lowest being $0.4 \mathrm{~g} . / 100 \mathrm{ml}$. Serum total cholesterol was high. Azotaemia and haematuria were absent or slight and transient.

Persistent symptomless proteinuria (2\%). These 3 boys did not have oedema, and proteinuria was discovered on routine urine tests carried out for unrelated purposes. Orthostatic proteinuria was excluded in all 3.

Chronic renal failure $(2 \%)$. Renal disease was unsuspected in any of these 3 boys until they were

Received January 24, 1969. admitted in chronic renal failure. One died soon after admission and the kidneys were examined at necropsy.

Post-streptococcal glomerulonephritis (15\%). In these 27 cases, 18 boys and 9 girls, the characteristic features of acute glomerulonephritis were recorded, and there was a history of a preceding streptococcal infection, or a raised antistreptolysin- 0 titre. In some cases the acute episode dated as far back as 2 months before the time of biopsy. The number represents only $9 \cdot 4 \%$ of all the cases of acute glomerulonephritis admitted into hospital during the period.

Schönlein-Henoch syndrome with renal involvement $(11 \%)$. The 19 cases, 8 boys and 11 girls, had skin lesions of the characteristic morphology and distribution, abdominal pain or intestinal haemorrhage, and joint symptoms. Proteinuria was taken to indicate renal involvement whether it was associated with haematuria or not. In 4 children proteinuria was heavy, the nephrotic syndrome appeared, and renal failure developed. In the others the proteinuria lasted from 6 weeks to 10 months.

Miscellaneous (3\%). This group consists of 1 boy and 1 girl with systemic lupus erythematosus and the nephrotic syndrome, and 1 case each of diphtheria, meningococcaemia, and Takayasu's arteriopathy.

\section{Renal Biopsy}

Renal biopsies were performed by the method of White (1963) and with his modification of the Silverman biopsy needle (1962). The biopsies were all taken by the same person (Y.C.T.). No death or serious complication was encountered in a total of 248 biopsies. Transient haematuria occurred in $38 \%$ of the patients, but in no instance was severe enough to require blood transfusion or surgical exploration of the kidney. Usually two pieces of tissue were obtained. One was used for ordinary histological examination, and the classification of Blainey et al. (1960) in an expanded form was applied. The other piece of tissue was studied by immunofluorescence techniques, as described by Chan and Tsao (1966). The use of fluoresceintagged antihuman IgG-globulin goat serum (Sylvana) was supplemented in later cases by tagged antihuman $\beta_{1 \mathrm{C}} / \beta_{1 \mathrm{~A}}$-globulin goat serum (Hyland). 
Differential protein-clearance studies. The method of Joachim et al. (1964) was used to compare the levels of individual proteins in a 24-hour specimen of urine with the plasma levels, and so to obtain a measure of clearance of each protein. The procedure used by Chan and Tsao (1966) was modified only in that the angle $\theta$, which is the measure of the selectivity of the proteinuria, was calculated by the method of least squares in place of a graphic estimation. The regression formula was:

$$
\tan \theta=\frac{\Sigma x y-\frac{\Sigma x \Sigma y}{n}}{\Sigma x^{2}-\frac{(\Sigma x)^{2}}{n}}
$$

where, $x=\log$ molecular weight of each protein; $y=\log \%$ clearance of each protein; $n=$ number of proteins estimated.

\section{Treatment Programme}

(a) Prednisone was the first drug used, and was given to 131 out of the 176 cases at a starting dose of $2 \mathrm{mg} . / \mathrm{kg}$. body weight per day, in 4 divided doses. It was continued until the disappearance of oedema and proteinuria as tested by the sulphosalicylic acid method; or where this was not possible to achieve, by a significant reduction in proteinuria and its stabilization at a low level. The dose was then reduced in stages to $1 \mathrm{mg} . / \mathrm{kg}$. body weight per day until the serum proteins returned to normal or were stabilized. Later the prednisone was reduced to the lowest level sufficient to control the proteinuria. Usually, the high dosage was maintained for 6 to 8 weeks and the reduced dosage for 12 to 18 months after disappearance of proteinuria. (b) Triamcinolone was substituted in equivalent doses in 7 cases in which prednisone did not evoke a satisfactory response and the same scheme was followed. Knapp and Cates (1966) called attention to cases responding to triamcinolone when prednisone failed. (c) Cyclophosphamide was used in doses of 3-5 mg./ kg. body weight per day in 23 cases in which steroid alone had failed, either alone or in combination with a steroid, for periods varying from 8 weeks to a year. Blood counts and $\mathrm{Hb}$ were estimated at least twice a week, and cyclophosphamide was stopped when the white cell count dropped below 4000/cu. mm.

Grading of response to treatment. A response was graded 'good' when there was no recurrence of proteinuria for at least a year after a complete remission. In a response graded 'satisfactory' the proteinuria recurred during the treatment period but responded promptly to raising the drug dosage again. A response was graded 'poor' when the proteinuria persisted in spite of treatment, irrespective of any symptomatic relief obtained.

\section{Results}

Histology. (1) Minimal lesions in glomeruli. These were found in 66 cases ( 51 boys and 15 girls) of jdiopathic nephrotic syndrome and in one case of symptomless proteinuria (38\%). The cellularity of the glomerular tufts was not increased and the capillary lumen was patent. Occasionally, particularly in cases in which proteinuria was heavy, the cytoplasm of the cells in the tuft appeared smudgy. The cytoplasm of the convoluted tubule cells was usually more granular than normal, and in some cases increased lipid was present in tubular cells, and this was associated with foam cells in the interstitial tissue. Minimal lesions were often so slight as not to be recognizable in every glomerulus.

(2) Diffuse membranous glomerulonephritis. This distinct morphological entity was found in biopsies from 14 cases of the whole series, 11 having idiopathic nephrotic syndrome, 2 having symptomless proteinuria, and one having chronic renal failure $(8 \%)$. Only 2 were female. It was characterized by the diffuse thickening of the basement membranes, which was most strikingly shown with the periodic acid-Schiff reagent. With the methenamine-silver stain the capillary wall appeared as two stained lines, the outer line being interrupted, spiky, or fimbriated, and the inner being continuous (Fig. 1). In the more chronic cases, fibrosis and sclerosis of glomeruli were present. Lipid-laden tubular cells and interstitial foamy macrophages were sometimes found in the medulla. The special features of 10 of these 14 cases have been described elsewhere (Chan and Tsao, 1966), and all are included here for comparison.

(3) Proliferative lesions. This type of lesion (Blainey et al., 1960) has been further subdivided into 3 morphological subtypes which can be related to different clinical presentations.

(a) Mild proliferation was found in biopsies of 42 of the cases (34 boys and 8 girls) of idiopathic nephrotic syndrome (24\%). Proliferation of endothelial and mesangial cells was present and was usually mild and sometimes involved only a peripheral lobule of the tuft (Fig. 2), so that some glomeruli appeared normal. Stalk formation was absent. The same lesion was observed in 1 other case classified as post-streptococcal glomerulonephritis on the basis of previous biopsies taken 24 and 10 months earlier, and in 3 other cases classified as Schönlein-Henoch syndrome.

(b) Proliferative lesions in post-streptococcal glomerulonephritis were found in all the 27 cases assigned on clinical grounds to this group (15\%) and in no others. The lesions were diffuse and were characterized by marked proliferation either as 


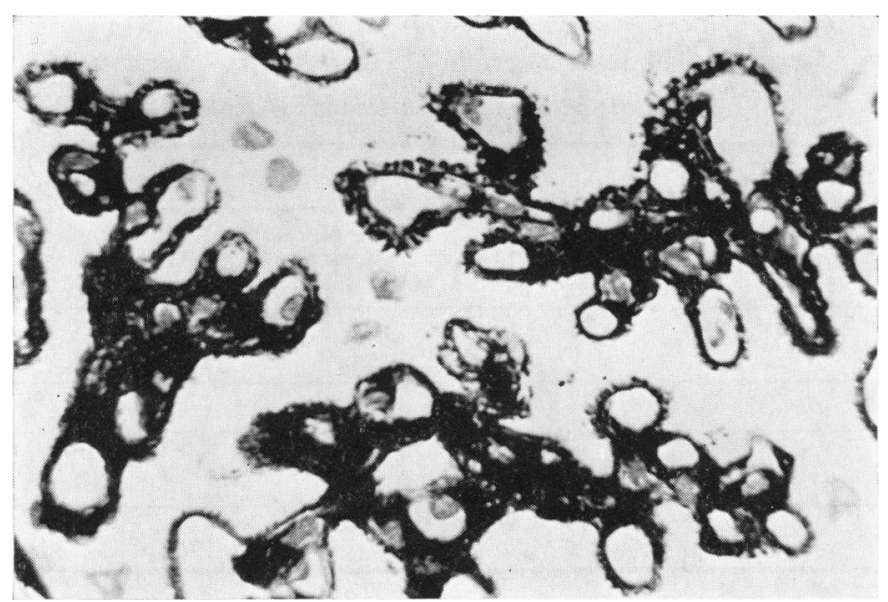

FIG. 1.-Glomerulus in membranous glomerulonephritis showing double silver-stained line of capillary wall. The outer line is interrupted and spiky or fimbriated, the inner one continuous. (Methenamine-silver stain $\times 700$.)

capsular crescents or as prominent lobular stalks formed by endothelial cells and mesangial cells of the glomeruli (Fig. 3). These appearances are described by Jennings and Earle (1961) as indicative of post-streptococcal glomerulonephritis. In 4 cases an exudation of polymorphonuclear leucocytes was also seen (Fig. 3).

(c) Proliferative lesions in Schönlein-Henoch syndrome. The histology varied widely in the 19 cases $(11 \%)$ in which this diagnosis was made

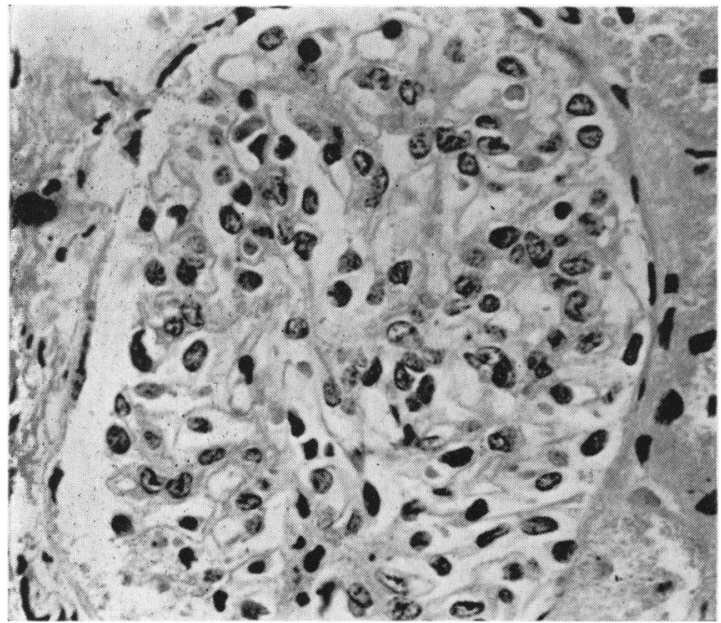

FIG. 2.-Glomerulus showing focal hypercellularity of mesangial cells in mild proliferative lesions. (H. and $E$. $\times$ 430.) on clinical grounds. It ranged from mild focal proliferation of capillary tufts indistinguishable from 'mild proliferation' in 3 cases, to marked proliferation of both capillary and capsular cells sometimes in the form of crescents. Capsular proliferation was sometimes so marked as to form a characteristic complete cuff surrounding and compressing an atrophic glomerular tuft (Fig. 4), and this is evidently a diagnostic feature. Even in very severe cases many glomeruli were completely spared.

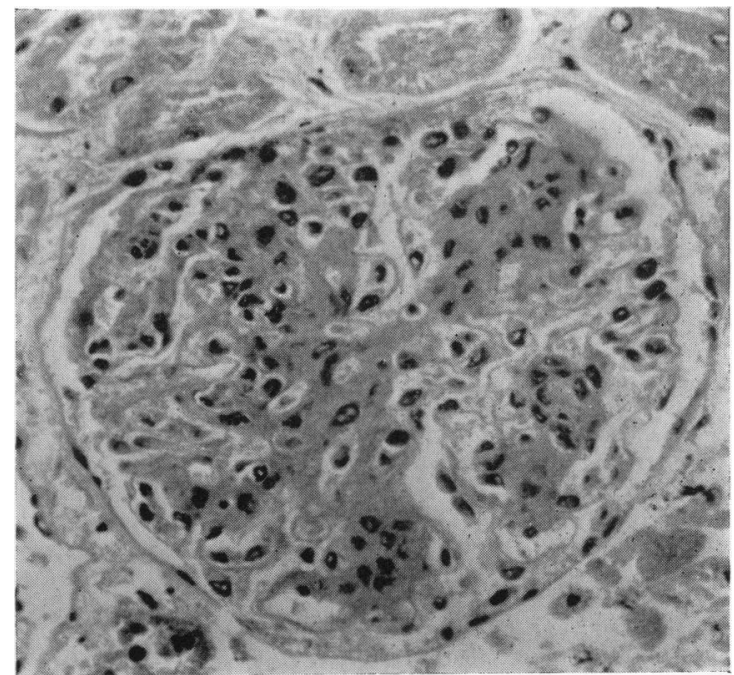

FIG. 3.-Glomerulus in post-streptococcal glomerulonephritis showing increased cellularity with lobulation of the tuft. Polymorphs are present. (H. and E. $\times 330$.) 
TABLE I

Immunofluorescent Staining for IgG and $\beta_{1 \mathrm{c}-\text {-globulins; }}$

Results in Cases of Different Groups

\begin{tabular}{|c|c|c|c|c|c|c|}
\hline \multirow[b]{2}{*}{ Globulin } & \multirow[b]{2}{*}{ Result } & \multirow[b]{2}{*}{$\begin{array}{l}\text { Minimal } \\
\text { Lesions } \\
\quad(1)\end{array}$} & \multirow[b]{2}{*}{$\begin{array}{l}\text { Membranous } \\
\text { Lesions } \\
(2)\end{array}$} & \multicolumn{3}{|c|}{ Proliferative Lesions (3) } \\
\hline & & & & $\begin{array}{l}\text { Mild Proliferative } \\
\text { Lesions } \\
\text { (3a) }\end{array}$ & $\begin{array}{l}\text { Post-streptococcal } \\
\text { Glomerulonephritis } \\
\text { (3b) }\end{array}$ & $\begin{array}{c}\text { Schönlein-Henoch } \\
\text { Syndrome } \\
(3 \mathrm{c})\end{array}$ \\
\hline \multirow[t]{2}{*}{ IgG } & $\begin{array}{l}\text { +ve } \\
\text { - ve }\end{array}$ & $\begin{array}{r}2 \\
54\end{array}$ & $\begin{array}{r}14 \\
0\end{array}$ & $\begin{array}{r}0 \\
20\end{array}$ & $\begin{array}{r}3 \\
19\end{array}$ & $\begin{array}{r}6 \\
13\end{array}$ \\
\hline & Total & 56 & 14 & 20 & 22 & 19 \\
\hline \multirow[t]{2}{*}{$\beta_{1 c}$} & $\begin{array}{l}\text { + ve } \\
\text { - ve }\end{array}$ & $\begin{array}{r}6 \\
10\end{array}$ & $\begin{array}{l}4 \\
0\end{array}$ & $\begin{array}{l}0 \\
9\end{array}$ & $\begin{array}{r}11 \\
7\end{array}$ & $\begin{array}{l}7 \\
4\end{array}$ \\
\hline & Total & 16 & 4 & 9 & 18 & 11 \\
\hline
\end{tabular}

(4) Extensive glomerulosclerosis (2 cases, 1\%). Sclerosis of glomeruli occurred to some extent in many long-standing cases, but in 2 of the 3 cases admitted in chronic renal failure the involvement was more extensive, half of the glomeruli in the biopsy being fibrosed in one case, and three-quarters of them in the other; in the former, the unsclerosed glomeruli showed minimal change.

(5) Lupus nephritis. There was a focal glomerulonephritis with patches of increased cellularity in the tufts and thickening or fibrinoid necrosis of the capillary wall, with the wire loop appearance in these 2 cases $(1 \%)$. In one a diffuse increase in cellularity was associated with the clinical findings of acute nephritis. In neither case were haematoxylin bodies demonstrable; and in both, LE cell preparations were positive.

(6) Others. No distinctive morphological change was recognizable in these 3 cases $(2 \%)$. In Takayasu's arteriopathy, the change in the renal tissue was mainly ischaemic and secondary to the arterial obstruction. In the single cases of diph-

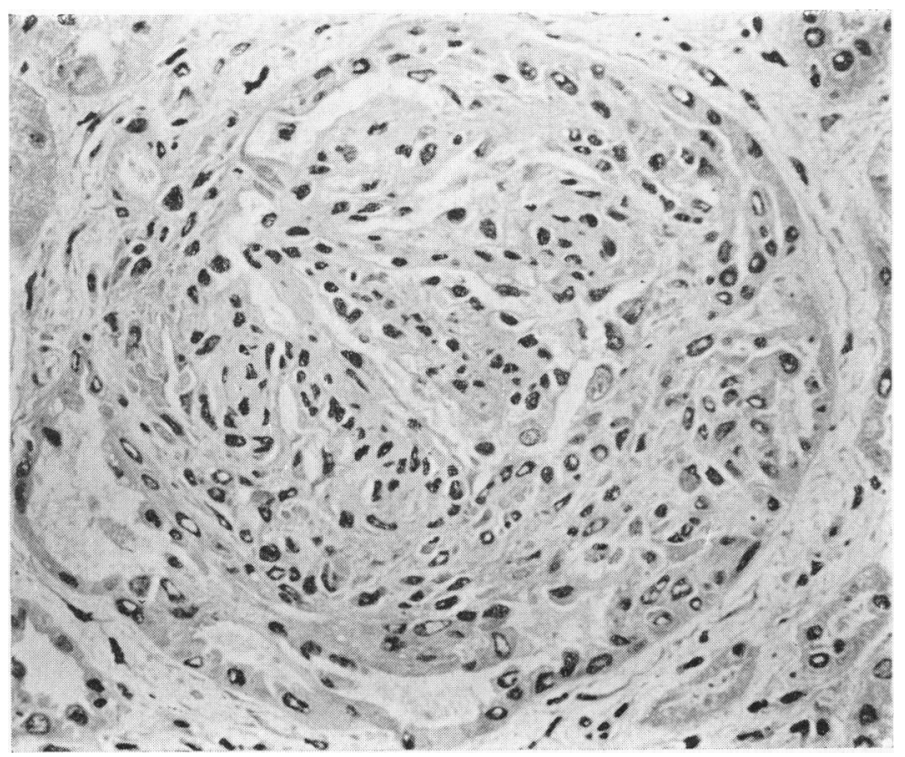

FIG. 4.-Glomerulus in Schönlein-Henoch syndrome showing marked proliferation of capsular cells, with complete cuff of capsular cells around atrophic tufts. (H. and E. $\times 300$.) 
theria and meningococcaemia, the changes were mainly in the tubular cells which showed marked hydropic vacuolation.

Immunofluorescence. This procedure was used in biopsies from 135 cases to identify the globulin IgG in the renal lesions and in 58 to identify $\beta_{1 C}$-globulin. The number of cases of the chief types studied and the results are shown in Table I. The procedure was performed serially in some patients, and the results used in Table I are those of the most active phase of the disease. In all cases in which IgG-globulin was found, $\beta_{1 \mathrm{C}}$ was present also. In membranous glomerulonephritis both globulins were consistently seen. IgG was present in all 14 before clinical remission was attained. The distribution of the IgG was characteristic, appearing as a roughly linear deposit along the capillary wall. This finding differs from that of R. T. McCluskey (1967, personal communication) who observed the protein in irregular clumps. In the 4 cases in which $\beta_{1 C}$-globulin was also tested for, it was seen in the same distribution as the IgG (Fig. 5). In 2 cases biopsied serially over a period in which they were entering a remission under treatment, the immunofluorescence was seen to diminish and finally to disappear, IgG first and $\beta_{1 \mathrm{C}}$ later. Consistent results were also obtained in the biopsies showing mild proliferative lesions in which neither kind of globulin was found in any of the cases.

The presence of the two globulins in the other morphological types of renal lesion was variable and less consistent (Table I). Of the biopsies in which the minimal glomerular lesion was found, only 2 out of 56 cases examined for IgG showed this

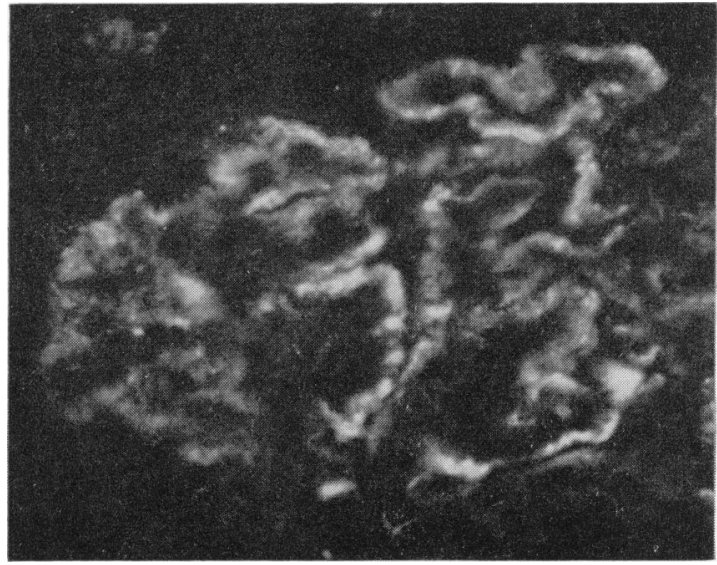

FIG. 6.-Glomerulus in post-streptococcal glomerulonephritis stained with labelled antihuman $\beta_{1 \mathrm{c}}-\mathrm{serum}$, showing stippled deposits of the protein. $(\times 510$.

globulin whereas 6 out of 16 cases examined for $\beta_{1 \mathrm{C}}$-globulin showed fluorescence though it was slight. In the proliferative lesion of post-streptococcal glomerulonephritis, IgG was present in only 3 out of the 22 cases examined, but $\beta_{1 \mathrm{C}}$ was present in 11 out of 18 cases. The globulins were less in amount and were distributed differently from those in the membranous nephritis, and beaded or stippled deposits were seen along capillary walls (Fig. 6). A similar occurrence and distribution of the two globulins was noted in the biopsies from the 19 cases with proliferative lesions associated with the Schönlein-Henoch syndrome: 8 cases were tested for IgG alone and 3 were positive. The other 11 cases were tested for IgG and $\beta_{1 \mathrm{C}^{-}}$

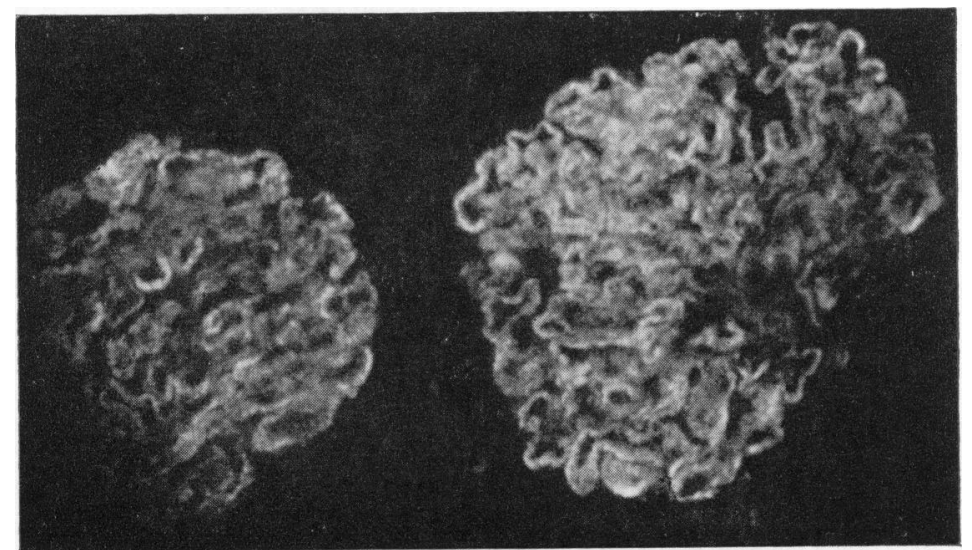

FIG. 5.-Two glomeruli in membranous glomerulonephritis stained with fluorescein-labelled antihuman $\beta_{1 \mathrm{C}}$-serum. Continuous lines of fluorescence indicate presence of the protein. $(\times 250$. 
globulins, and both were shown in 3 and $\beta_{1 C^{-}}$ globulin only in 4 . The distribution was patchy in that only a proportion of the glomeruli of the positive cases was affected, and the involvement of the affected glomerulus was focal. In one case, however, large amounts of both globulins were found in all glomeruli in the biopsy, and, on casual examination, the distribution resembled that found in membranous glomerulonephritis.

Neither of the two cases of extensive glomerulosclerosis showed the globulins in the renal tissue. Only one of the two cases of lupus nephritis was studied by immunofluorescence. IgG was found distributed focally and particularly in the region of 'wire loops': $\beta_{1 \mathrm{C}}$ was not stained for. The two globulins were not found in the renal tissue of the patient with Takayasu's disease, and immunofluorescence staining was not applied to the renal tissue of the diphtheria or meningococcaemia cases.

\section{Results of Treatment}

Steroids. Prednisone was used initially in the 119 cases presenting with the idiopathic nephrotic syndrome and in the 3 cases with symptomless proteinuria. With these clinical presentations the best response to treatment (Table II) was seen in 67 cases with the minimal type of lesion. A good response with clearance of proteinuria and no recurrence for at least a year was recorded in 49 out of 67 cases $(73 \%)$ and a satisfactory response in $21 \%$. In 43 patients with the mild proliferative type of lesion associated with the nephrotic syn-

\section{TABLE II}

Clinical Responses to Steroid Treatment of Cases in Different Groups

\begin{tabular}{|c|c|c|c|c|c|}
\hline \multirow{2}{*}{ Groups } & \multicolumn{4}{|c|}{ Responses } & \multirow{2}{*}{ Totals } \\
\hline & Good & $\begin{array}{l}\text { Satis- } \\
\text { factory }\end{array}$ & Poor & $\underset{\text { certain }}{\text { Un- }}$ & \\
\hline $\begin{array}{l}\text { 1: Minimal lesions } \\
\text { 2: Membranous } \\
\text { glomerulonephritis } \\
\text { 3: Proliferative lesions } \\
\text { (a) Mild prolifer- } \\
\text { ative } \\
\text { (b) Post-strepto- } \\
\text { coccal nephritis } \\
\text { (c) Schönlein- } \\
\text { Henoch } \\
\text { syndrome } \\
\text { 5: Lupus nephritis }\end{array}$ & $\begin{array}{r}25 \\
-\end{array}$ & $\begin{array}{c}14(1) \\
-\end{array}$ & $\begin{array}{l}4(4) \\
2(2) \\
4(3) \\
2\end{array}$ & $\begin{array}{l}- \\
-\end{array}$ & $\begin{array}{l}67 \\
13\end{array}$ \\
\hline
\end{tabular}

Numbers in brackets are the numbers of cases subsequently treated with cyclophosphamide.

$\star$ Trial inadequate to assess result.
TABLE III

Clinical Responses to Cyclophosphamide Treatment in Steroid-resistant Cases

\begin{tabular}{|c|c|c|c|c|c|}
\hline \multirow[b]{2}{*}{ Groups } & \multicolumn{4}{|c|}{ Responses } & \multirow[b]{2}{*}{ Totals } \\
\hline & Good & $\begin{array}{l}\text { Satis- } \\
\text { factory }\end{array}$ & Poor & $\begin{array}{l}\text { Un- } \\
\text { certain }\end{array}$ & \\
\hline $\begin{array}{l}\text { 1: Minimal lesions } \\
\text { Nephrotic syndrome } \\
\text { Symptomless } \\
\text { proteinuria } \\
\text { 2: Membranous } \\
\text { glomerulonephritis } \\
\text { 3: Proliferative lesions } \\
\text { (a) Mild prolifer- } \\
\text { ative } \\
\text { (b) Post-strepto- } \\
\text { coccal nephritis } \\
\text { (c) Schönlein- } \\
\text { Henoch syndrome }\end{array}$ & $\begin{array}{r}2 \\
- \\
-\end{array}$ & $\begin{array}{r}2 \\
- \\
-\end{array}$ & $\begin{array}{c}1+ \\
1 \\
3\end{array}$ & $\begin{array}{r}2 \\
1 \\
-\end{array}$ & $\begin{array}{l}7 \\
2 \\
3\end{array}$ \\
\hline
\end{tabular}

$\star$ Trial inadequate to assess result.

$\dagger$ Remission on subsequent triamcinolone.

$¥$ Remission after all drugs stopped.

drome, $58 \%$ showed a good response and $33 \%$ a satisfactory one. In membranous glomerulonephritis 13 cases were treated with steroid and $4(31 \%)$ showed a good response and none a satisfactory one. Of the 19 patients with the Schönlein-Henoch syndrome only 4, all with the nephrotic syndrome, were given treatment when proteinuria did not clear spontaneously and all responded poorly. Proteinuria eventually cleared spontaneously in 25 out of the 27 cases of post-streptococcal glomerulonephritis; only 2 of these cases, both with the nephrotic syndrome, were treated with steroids and the results were poor in both. In all these 6 cases with severe proliferative lesions treated with steroids, proteinuria continued to be heavy, and gross oedema persisted when prednisone and triamcinolone were given.

Cyclophosphamide was used in 23 cases after steroid therapy had failed. The results are shown in Table III. A good response was obtained in 7 cases.

Complications of treatment and variations in response. Varying degrees of steroid resistance were encountered with all types of renal lesion (Table II). The treatment led to some symptomatic relief, however, in all but one of the cases presenting as idiopathic nephrotic syndrome. The exception was a case of membranous glomerulonephritis with proteinuria of poor selectivity $\left(\theta=59^{\circ}\right)$; oedema persisted and death occurred from Shigella flexneri dysentery and septicaemia, in the course of prednisone and cyclophosphamide treatment. Symptoms of steroid toxicity such as Cushingoid 


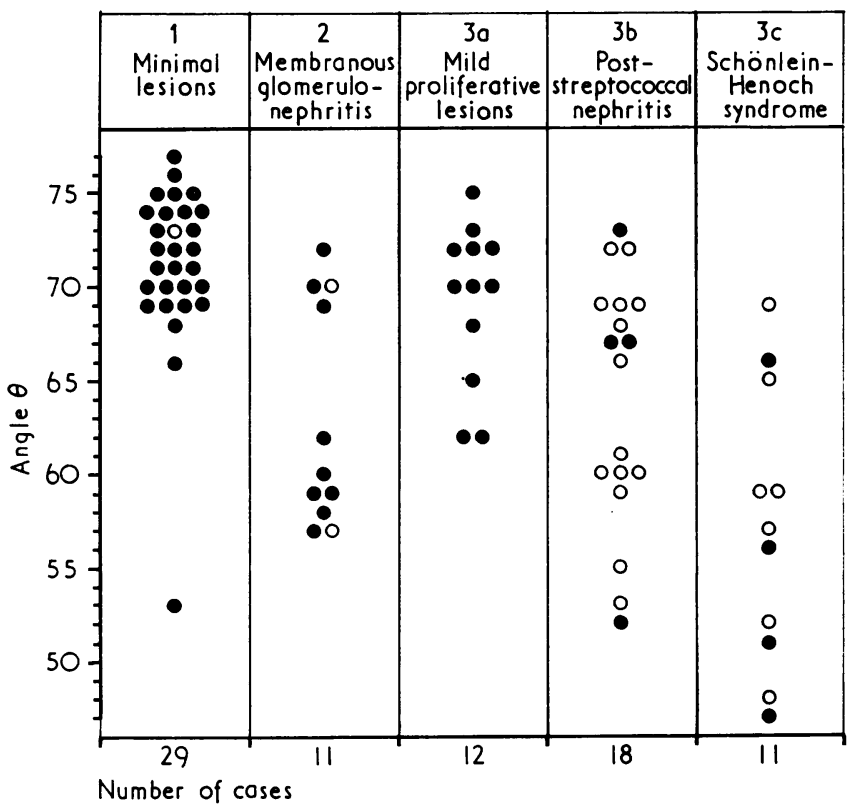

FIG. 7.-Selectivity of proteinuria before treatment in 81 individual cases in different groups, and expressed as degrees of angle $\theta$. Each circle represents one case. Cases with the nephrotic syndrome are represented by solid circles.

facies, hirsutism, and retardation of growth were encountered frequently but deterioration such as gross haematuria, the onset of hypertensive symptoms or renal failure necessitated withdrawal of the drug only in the 2 cases of persistent post-streptococcal glomerulonephritis and 4 cases of Schönlein-Henoch syndrome treated.

Cyclophosphamide was used in 5 of these 6 cases with severe proliferative lesions but without improvement (Table III), in contrast to the good results with cyclophosphamide in 7 of the 17 cases with the idiopathic nephrotic syndrome so treated.

In a 7-year-old boy with post-streptococcal glomerulonephritis the proteinuria disappeared over a period of 22 months without any specific treatment though crescents and later adhesions were seen in repeated biopsies. In the last biopsy mild focal proliferation was the only active element seen and 2 out of 13 glomeruli examined were sclerosed. In one of the cases with minimal lesions and the nephrotic syndrome in which both cyclophosphamide and prednisone had failed to evoke a satisfactory response (Table III), a remission was obtained later when triamcinolone was given alone. Among the cases with mild proliferative lesions, one underwent spontaneous remission after all drugs had been tried unsuccessfully (Table III).

Only a longer-term assessment will determine how many cases are steroid dependent, and already in a few cases in which remission has justified termination of the treatment, subsequent relapse has led to its reinstitution.

\section{Selectivity of Proteinuria}

The selectivity of the proteinuria was measured in 81 cases (Fig. 7). All of them were subsequently treated with steroids and they comprise two-thirds of the 131 cases treated in this way.

Of the 29 cases with the minimal type of lesion 28 had idiopathic nephrotic syndrome and 1 had persistent proteinuria only; they generally showed a high degree of selectivity, and in 27 of them the angle $\theta$ was $68^{\circ}$ or more. The lowest value was obtained in a case of incipient chronic renal failure. A good response to steroid treatment was found in 23 of the 29 and in all of them $\theta$ was $68^{\circ}$ or greater. The response to steroid was only satisfactory, however, in 3 cases with angles of $72^{\circ}, 70^{\circ}$, and $69^{\circ}$, and poor in 3 other cases with angles of $73^{\circ}, 66^{\circ}$, and $53^{\circ}$. There is a clear correlation between a high angle and a good response to treatment, but it is not absolute.

In the 11 cases of membranous glomerulonephritis in which selectivity was tested, there was a scatter of selectivity angles in two clusters (Fig. 7) around $70^{\circ}$ and $59^{\circ}$. A low angle of $57^{\circ}$ was found in one case of symptomless proteinuria, with these 
lesions in the biopsy. Of the 5 cases with selectivity angles $69^{\circ}$ or more, 4 responded well to steroid therapy, whereas of the 7 with angles $\theta 57$ to $62^{\circ}$, 6 responded badly and in only 1 was the response good. Selectivity measurements thus give in general an indication of the prognosis with steroid therapy in this morphological type of idiopathic persistent proteinuria. This correlation has been reported previously (Chan and Tsao, 1966).

In the 41 cases of the proliferative types of lesion in which selectivity measurements were carried out, the scatter of the values varied in the three subtypes. High selectivity with $\theta 62^{\circ}$ or greater was encountered among the 12 cases tested with mild proliferative lesions, all of which presented as idiopathic nephrotic syndrome. In 5 of them, including those with the highest angles, the response to steroid treatment was good, but in 5 others with selectivity angles ranging from $72^{\circ}$ to $65^{\circ}$ the response was only satisfactory; the 2 cases showing a poor response were those with the lowest values of $62^{\circ}$. Thus, in this group also a correlation exists between the selectivity angle and the response to treatment. Repetition of selectivity measurements in some cases of all these different types of lesion confirmed in general the observation of Cameron and White (1965) that this index remains remarkably constant over prolonged periods regardless of treatment.

In the 18 cases with lesions of post-streptococcal nephritis tested and in the 11 cases of SchönleinHenoch syndrome taken together, the scatter of the selectivity measurements was less consistent (Fig. 7). Serial clearance studies in one case of poststreptococcal nephritis showed angles of $61^{\circ}$, $54^{\circ}, 56^{\circ}$, and $59^{\circ}$ over a period of 4 weeks, and in another case $\theta$ changed from $43^{\circ}$ to $69^{\circ}$ in 7 days. Serial studies in the Schönlein-Henoch syndrome showed similar variations, e.g. $60^{\circ}$ to $69^{\circ}$ in 7 weeks. Marked improvement in selectivity occurred when haematuria cleared up. Some exceptionally low selectivity angles in other cases of these two conditions may be related to coexistent haematuria also. Only 2 cases of post-streptococcal nephritis were treated with steroids; the selectivity angles being $67^{\circ}$ in both, and both responded poorly to treatment. The selectivity angles were measured in 3 of the 4 cases of Schönlein-Henoch syndrome treated with prednisone, and were $66^{\circ}, 56^{\circ}$, and $47^{\circ}$; all 3 deteriorated on treatment.

\section{Discussion}

This account of 176 cases of persistent proteinuria in children in Hong Kong corresponds in many respects to what has been described in the nephrotic syndrome in childhood elsewhere (White, 1967; Cameron, 1968). The condition affects males chiefly, and the aetiology is often obscure. Malaria, which leads to the nephrotic syndrome in African children (Kibukamusoke, 1968), is rare in Hong Kong now, and amyloid, a common cause of the nephrotic syndrome in adults in India (Vaishnava and Gulati, 1966) is very seldom seen at any age. The incidence of $8 \%$ of cases of diffuse membranous glomerulonephritis in our series is, however, unusually high; the incidence is high in France also (Habib, 1968).

The best response to corticosteroid treatment (Table II) was obtained in cases with minimal lesions in which $94 \%$ of the results were good or satisfactory. The equivalent figure was $91 \%$ in cases with mild proliferative lesions. Longer follow-up (Arneil and Lam, 1966) may alter these assessments, but our definition of a good response as a remission of one year excludes cases with prompt relapses. The only cases of post-streptococcal nephritis or Schönlein-Henoch syndrome treated with steroids were those with the nephrotic syndrome and the treatment yielded discouraging results, as White, Cameron, and Trounce (1966) found, and was not free from danger. Nevertheless, in other cases of Schönlein-Henoch syndrome not in this series and in which renal damage appeared to be slight, we have used steroids to control symptoms without impairing kidney function.

White (1967) noted a dramatic early favourable response to cytotoxic drugs in most of his steroiddependent cases of idiopathic nephrotic syndrome; our experience with cyclophosphamide (Table III) is less good but still encouraging, at least in the idiopathic cases.

The clinical presentation of the cases divides them into those with a known underlying condition and those with idiopathic proteinuria. 27 cases were assigned to the group of post-streptococcal nephritis and 19 to the Schönlein-Henoch syndrome on the basis of clinical diagnosis; biopsies from each of these groups showed a consistent range of histological lesions.

In most of the other cases the cause of the proteinuria was unknown. The presentation was idiopathic nephrotic syndrome in 119 and symptomless persistent proteinuria in 3 . In 13 of them however, the lesions of membranous glomerulonephritis were seen on biopsy (Fig. 1) and the consistent presence of the globulins IgG and $\beta_{1 \mathrm{C}}$ in the glomeruli (Fig. 5) confirmed the separation of this group from the others. When these cases of membranous glomerulonephritis are excluded, there 
remain 67 cases with lesions of minimal and 42 with lesions of mild proliferative type (Fig. 2) which are truly idiopathic and which present particular difficulties in classification. The assignment of individual cases to the minimal or mild proliferative groups depends entirely on histological criteria, and no other tests discriminate between them. Nevertheless, taken as a whole, the cases with minimal lesions show a higher selectivity of proteinuria (Fig. 7) and a better response to corticosteroid therapy (Table II) than those with mild proliferative lesions, and the incidence of globulins in the lesions of the two groups is not identical (Table I). IgG and $\beta_{1 \mathrm{C}}$ were consistently absent from cases with mild proliferative lesions, but in 6 out of the 16 biopsies of minimal lesions $\beta_{1 \mathrm{C}}$ was identified and IgG in a few. We have continued then to use this conventional classification, though probably neither group is homogeneous.

Possibly the 6 cases with minimal lesions in which $\beta_{1 C}$-globulin was seen in the glomeruli were actually post-streptococcal nephritis undergoing resolution, but there is no other evidence for this view. The specificity of the mild proliferative type of lesion (Fig. 2) is also questionable. In one of our cases of post-streptococcal nephritis, 2 serial biopsies showed the usual mesangial stalks, but in a third biopsy, taken 10 months later, the lesions were indistinguishable from those classified as mild proliferation. The histological changes found in 3 cases of Schönlein-Henoch syndrome also satisfied the criteria of mild proliferation. There is no direct evidence, however, that any of the cases we have assigned to the mild proliferation group originated in a streptococcal infection or in an attack of purpura.

Ogg, Cameron, and White (1968) have redefined the histological criteria for the study of renal biopsies in the nephrotic syndrome, and they have now abandoned the term 'mild proliferative lesions'. This new classification is used in the large series of cases of the nephrotic syndrome reported by Cameron (1968), in which $48 \%$ of the biopsies taken from children were found to show minimal lesions, in comparison with $38 \%$ of our cases. Cameron stated that most of the cases previously diagnosed as mild proliferation were now allocated to the group with minimal lesions, but his incidence of proliferative lesions was $30 \%$ as against the total of $16 \%$ of cases of post-streptococcal nephritis and extensive glomerulosclerosis in our series with which it can be compared. More evidence, particularly on the evolution of post-streptococcal nephritis, is required before the real status of minimal lesions or of mild proliferation can be decided.

Selectivity of proteinuria was expressed graphically by Blainey et al. (1960) who determined the clearances of 6 plasma proteins identified immunologically. Joachim et al. (1964) estimated clearances of the same and some other proteins, but expressed the degree of selectivity as the angle $\theta$ and their method has been adopted here. Though laborious and expensive the use of 5 or more proteins seems preferable at present in this estimation to the measurement of only 2 proteins, if only because there is no agreement as to which 2 proteins should be assayed (Cameron and Blandford, 1966; MacLean and Robson, 1967). The selectivity of proteinuria is generally higher in children than in adults (Cameron and White, 1965). The value of the technique and its variations is prognostic rather than diagnostic, and depends on the extent to which the results discriminate between cases that will respond to steroid therapy and those that will not.

The degree of selectivity was found to have discriminative value in assessing the response of most cases of membranous glomerulonephritis to steroid treatment. Selectivity was almost invariably high in our cases with minimal lesions (Fig. 7), and only a few low angles were found in the group with mild proliferative lesions in the glomeruli. In a series of adult and childhood cases of nephrotic syndrome, Cameron (1968) found the relation between high selectivities and good responses to steroid therapy, 'to be almost entirely dependent on the relationship that minimal change histology has, on the one hand, with highly selective protein clearances and, on the other, with steroid response'. Our results (Fig. 7) not only confirm the association within the group with minimal lesions, but show a correlation also with cases of membranous glomerulonephritis and with our group of mild proliferative lesions. Measurements of selectivity then give a valuable though not an absolute indication of the response to steroid treatment of cases of persistent proteinuria that are idiopathic. In our experience it is possible to diagnose accurately, by means other than biopsy, post-streptococcal nephritis and the Schönlein-Henoch syndrome, and to predict the range of lesions that will be found in the biopsies on these cases. It is undesirable to treat the nephrotic syndrome in these cases with corticosteroids, but, in any case, the angle $\theta$ is often low (Fig. 7), sometimes on account of haematuria. Cameron (1968) came to the conclusion that where the minimal type of lesion 'may be expected in the bulk of the patients, an 8-week course of corticosteroid therapy may be 
begun without an initial biopsy and with a high expectation of success'. When allowance is made for differences in terminology, the proportion of such cases in this series from Hong Kong approaches that of Cameron, and analysis of our results would also justify starting corticosteroid therapy in cases of idiopathic persistent proteinuria in children on the basis of the selectivity measurements.

The demonstration of the globulins IgG and $\beta_{1 C}$ in the glomeruli (Table I) did not provide a satisfactory general basis of classification, but both globulins were identified consistently in membranous glomerulonephritis. Ogg et al. (1968) reported consistently normal levels of $\beta_{1}$ globulin in estimations of this $\mathrm{C}^{\prime} 3$ component of complement in plasma samples in this type of nephritis. Chan and Tsao (1966) have reported a diminution of IgG during steroid-induced remissions in 2 of our cases of this condition. In the extended observations in the present study, 2 more cases underwent remissions on steroid therapy alone and 3 others when an immunosuppressive drug was used. In serial biopsies on all these 7 cases the globulins in the glomeruli were observed to decrease and finally to disappear, IgG first and $\beta_{1 \mathrm{C}}$ later as part of the favourable response to the treatment. This encouraging result in diffuse membranous glomerulonephritis contrasts with the uniformly poor response reported in adults (Blainey et al., 1960). Nevertheless, though the disappearance of the globulins seems to confirm a cessation in the activity of the disease process, the histological changes have persisted, and it is uncertain what the long-term outcome in these children will be.

Immunofluorescent staining for the globulins was positive in only a proportion of the proliferative lesions and was entirely absent from mild proliferative lesions (Table I). In all the positive cases of the proliferative types and also in the positive cases with minimal lesions, the fluorescence appeared stippled or beaded (Fig. 6), like that described by Michael et al. (1966) as 'immune deposit disease', and unlike that in diffuse membranous glomerulonephritis (Fig. 5). It has been suggested (Michael et al., 1964) that conditions in which IgG is associated with the glomerular lesions are likely to be resistant to steroid treatment In our study, $\beta_{1 \mathrm{C}}$-globulin was also identified, and it was shown more often than was IgG; no case was found which was positive for IgG and negative for $\beta_{1 \mathrm{C}}$. Follow-up studies in these patients seem to indicate that in other conditions as well as diffuse membranous glomerulonephritis the presence of the globulins is related to the activity of the disease process. When staining becomes negative, complete disappearance of proteinuria in that case can be anticipated shortly.

\section{Summary}

Renal biopsies were carried out in 129 boys and 47 girls aged from 2 to 12 years with proteinuria of more than 3 weeks' duration. Biopsies from 135 of the cases were studied by an immunofluorescence technique to identify the globulins IgG and $\beta_{1 \mathrm{C}}$ in the lesions. In 81 cases differential clearances of proteins in the urine were estimated. The results are correlated with the response of the proteinuria to treatment with steroids in 131 of the cases supplemented with or replaced by immunosuppressive therapy in 23.

The proteinuria was symptomless in $2 \%$ of cases, and the idiopathic nephrotic syndrome was present in $67 \%$. Post-streptococcal glomerulonephritis was diagnosed clinically in $15 \%$ and Schönlein-Henoch syndrome in $11 \%$, the lesions in these two conditions being consistent and predictable within a range.

Among the 119 cases of idiopathic nephrotic syndrome, diffuse membranous glomerulonephritis was diagnosed histologically in $11(9.2 \%)$, and this lesion was found in 3 additional cases; a total of $8 \%$ of the whole series. The other idiopathic cases were classified on histological grounds into a group of 66 cases with minimal and a group of 42 cases with mild proliferative lesions.

Steroid treatment was followed by remissions of 1 year or more in $73 \%$ of cases with minimal lesions, in $58 \%$ of cases with mild proliferative lesions, and in $30 \%$ of cases with membranous glomerulonephritis.

The measurement of selectivity of proteinuria by differential protein clearance studies offers a valuable prognostic guide in the steroid treatment of children with persistent idiopathic proteinuria, including those with membranous glomerulonephritis. It is of dubious value in post-streptococcal nephritis and the Schönlein-Henoch syndrome, and is vitiated by the presence of haematuria.

$\beta_{1 C}-$ globulin was demonstrated more often than IgG in all conditions in which it was present. It was consistently present in the glomeruli in membranous glomerulonephritis, and in many cases of post-streptococcal glomerulonephritis and of Schönlein-Henoch syndrome. Globulins were absent from all cases with mild proliferative lesions. The globulins were deposited in a characteristic linear pattern in membranous glomerulonephritis and as stippled or beaded areas of fluorescence in other conditions. Their 
presence may be related to the activity of the disease process.

We wish to thank the Li Shu Fan Medical Foundation for generous financial support, and Professor C. E. Field for kind encouragement. Mr. K. H. Lau gave valuable technical assistance.

\section{REFERENCES}

Arneil, G. C., and Lam, C. N. (1966). Long-term assessment of steroid therapy in childhood nephrosis. Lancet, 2, 819.

Blainey, J. D., Brewer, D. B., Hardwicke, J., and Soothill, J. F. (1960). The nephrotic syndrome: diagnosis by renal biopsy and biochemical and immunological analyses related to the response to steroid therapy. Quart $\mathcal{F}$. Med., 29, 235.

Cameron, J. S. (1968). Histology, protein clearances, and response to treatment in the nephrotic syndrome. Brit. med. $\mathcal{7} ., 4,352$.

- , and Blandford, G. (1966). The simple assessment of selectivity in heavy proteinuria. Lancet, 2, 242.

- and White, R. H. R. (1965). Selectivity of proteinuria in children with the nephrotic syndrome. ibid., 1, 463.

Chan, W. C., and Tsao, Y. C. (1966). Diffuse membranous glomerulonephritis in children. 7 . clin. Path., 19, 464.

Habib, R. (1968). Personal communication to Cameron (1968).

Jennings, R. B., and Earle, D. P. (1961). Post-streptococcal glomerulonephritis: histopathologic and clinical studies of the acute, subsiding acute and early chronic latent phases. $\mathcal{F}$. clin. Invest., 40, 1525.

Joachim, G. R., Cameron, J. S., Schwartz, M., and Becker, E. L. (1964). Selectivity of protein excretion in patients with the nephrotic syndrome. ibid., 43, 2332.
Kibukamusoke, J. W. (1968). Nephrotic syndrome and chronic renal disease in the tropics. Brit. med. $\mathcal{F} ., 2,33$.

Knapp, M. S., and Cates, J. E. (1966). Steroid-resistant nephrotic syndrome. Lancet, 1, 930.

MacLean, P. R., and Robson, J. S. (1967). A simple method for determining selectivity of proteinuria. ibid., 1,539 .

Michael, A. F, Drummond, K. N. Good, R. A, and Vernier, R. L. (1964). Immunoglobulins: clarification of their significance in renal disease and demonstration of response to immunosuppressive therapy. F. clin. Invest., 43, 1291.

- - - , and $\longrightarrow$ (1966). Acute poststreptococcal glomerulonephritis: immune deposit disease. ibid., 45, 237.

Ogg, C. S., Cameron, J. S., and White, R. H. R. (1968). The $C^{\prime} 3$ component of complement ( $\beta_{11}$-globulin) in patients with heavy proteinuria. Lancet, $2,78$.

Vaishnava, H., and Gulati, P. D. (1966). Nephrotic syndrome in India. ibid., 2, 912.

White, R. H. R. (1962). A modified Silverman biopsy needle for use in children, ibid., 1, 673.

- (1963). Observations on percutaneous renal biopsy in children. Arch. Dis. Childh., 38, 260.

- (1967). Cytotoxic drug therapy in steroid-resistant glomerulonephritis. Proc. roy. Soc. Med., 60, 1164.

—- Cameron, J. S., and Trounce, J. R. (1966). Immunosuppressive therapy in steroid-resistant proliferative glomerulonephritis accompanied by the nephrotic syndrome. Brit. med. F., $2,853$.

Correspondence to Dr. W. C. Chan, Department of Pathology, Queen Mary Hospital Compound, Hong Kong. 